\title{
Adaptive Voltage Control for Large Scale Solar PV Power Plant Considering Real Life Factors
}

\author{
Hazem Karbouj, Zakir Hussain Rather, Member, IEEE and Bikash C. Pal, Fellow, IEEE
}

\begin{abstract}
This paper presents an accurate and realistic estimation of reactive power capability of solar photovoltaic (PV) inverters considering ambient temperature, solar irradiance, and terminal voltage. Based on the accurate estimation of reactive power capability, a self-adaptive voltage controller is proposed to enable solar PV power plant participation in voltage control ancillary service. The proposed accurate and realistic estimation has revealed the possibility of solar PV power plant failing to comply with grid code requirements under extreme weather conditions. On the other hand, the proposed control strategy has shown significantly better effectiveness to utilise solar PV inverter capability, and provide better voltage control support service to the grid.
\end{abstract}

Index Terms-Ancillary service, reactive power capability, large scale solar PV power plant.

\section{INTRODUCTION}

Grid integration of solar photovoltaic (PV) power has recently experienced a significant shift from rooftop installation to large utility scale solar PV power plant, which can be attributed to several factors, such as falling prices of solar PV technology, regulatory and policy measures for large scale renewable energy integration. GW-scale solar PV power plants (PVPP) are currently under construction or already in operation in various places around the world. In India, for example, $2 \mathrm{GW}$ large scale PVPP is partly in operation, with two other PVPP of 2.25 and $5 \mathrm{GW}$ under construction [1].

Due to displacement of conventional generation by large scale PVPP and other renewable energy sources (RESs), transmission system operators (TSOs) encounter various challenges in secure and stable operation of RES integrated power systems, particularly, at high RES penetration level. RES driven displacement of synchronous machines, the main source of dynamic reactive power in conventional power systems, result in diminished reactive power reserve and poor dynamic voltage control in the power system. Several countries are already facing diminishing reactive power issue due to high RES penetration, and these countries are tackling such issues through several measures, such as, installing new synchronous condensers [2], and procuring reactive power from ancillary service market [3]. Therefore, in large-scale RES integrated power system, renewable energy power plants, including large scale PVPP, are required to provide dynamic reactive power and voltage control support for secure and stable grid operation. In large-scale solar PV power integrated systems, large scale PVPP are expected to take leading role in grid voltage

H. Karbouj and Z. H. Rather are with the Department of Energy Science and Engineering, Indian Institute of Technology Bombay, Mumbai 400076, India (e-mail: \{hazem.karbouj \& zakir.rather\}@iitb.ac.in). B. C. Pal is with the Department of Electrical and Electronic Engineering, Imperial College London, London SW7 2AZ, U.K (e-mail: b.pal@imperial.ac.uk). control beyond current mandatory grid code requirements, potentially through procurement of such service in ancillary service market or by mandating such services from large scale PVPP.

Solar PV inverters can actively participate in reactive power support in daylight and night-time [4], [5]. Currently rooftop solar PV inverters are not required to participate in voltage control/dynamic reactive power control. However, large scale PVPP, typically connected at transmission voltage level, are required to participate in dynamic voltage control [6]. The authors in [7] presented a field implementation of $300 \mathrm{MW}$ solar PV power plant participating in dynamic reactive power support, and plant's compliance with grid code regulations. The authors in [8] and [9] presented control strategies to utilize solar PV inverters as reactive power static compensators (STATCOM) during day and night-time. Moreover, the authors in [10] and [11] analysed the cost of operating a solar PV power plant at night as STATCOM. However, while the related studies reported in the literature so far have focused on reactive power support from solar PV inverters/plants, all the studies have ignored accurate calculation or estimation of reactive power (Q) capability of such inverter interfaced solar PV systems, as several practical factors, particularly, weather conditions, can significantly affect actual reactive power capability of such plants.

This paper addresses the above stated practical limitations through two main contributions, viz.: i) A methodology for accurate calculation of solar PV inverter reactive power capability considering ambient temperature, solar irradiance and inverter terminal voltage has been proposed to find realistic reactive power support capability of solar PV plant, and ii) Based on the accurate estimation of reactive power capability, a self-adaptive voltage control is proposed to enable large scale PVPP participation in voltage control ancillary service. Accurate reactive power capability of solar PV inverters is calculated under extreme weather conditions for two locations in Saudi Arabia and India. The proposed Q capability calculation is compared with the existing conventional approach that does not consider effect of ambient temperature and inverter terminal voltage on reactive power capability of solar PV inverters. The proposed methodology of $\mathrm{Q}$ capability calculation and self-adaptive voltage control scheme has been validated on a PVPP integrated IEEE 39 bus system developed in DIgSILENT PowerFactory platform, with detailed modelling of PVPP.

The rest of the paper is organised as follows, in Section II mandatory reactive power requirements from PVPP is discussed for different grid code regulations. Accurate reactive power capability of solar PV inverter is formulated in Section 


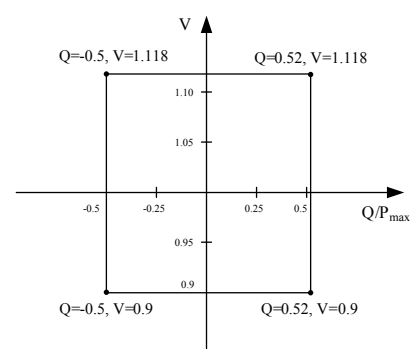

Ireland(EirGrid)

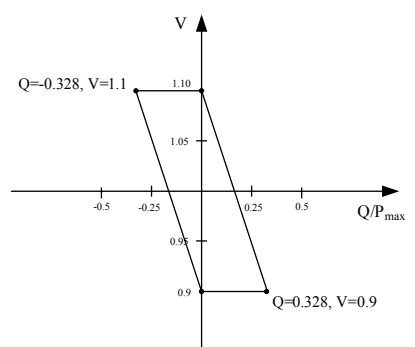

USA (CAISO)

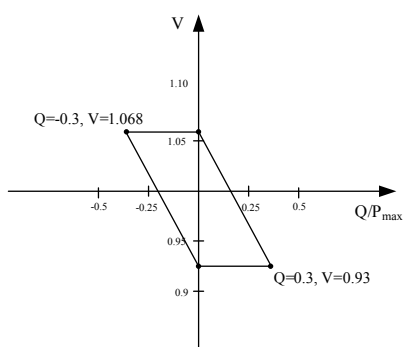

Spain(REE)

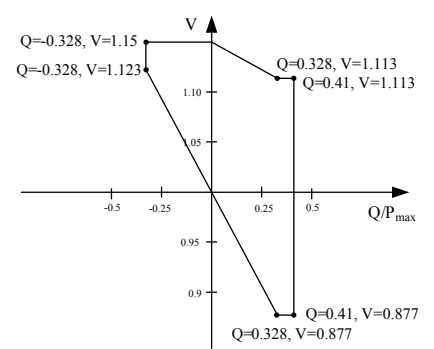

Germany(TenneT)

Fig. 1: Reactive power requirements from large scale PVPP for different countries under different voltage magnitudes. Irish requirements are for $110 \mathrm{kV}$ and $220 \mathrm{kV}$ grids. Spanish and German requirements are for $220 \mathrm{kV}$ grid. [7], [12]-[14]

III. The proposed self-adaptive voltage controller is presented in Section IV. Results are presented in Section V. The paper is discussed and concluded in Section VI.

\section{Mandated Reactive Power ReQuirements From LARGE SCALE PVPP}

\section{A. Mandated Reactive Power Requirements from large scale $P V P P$}

System regulators/TSOs require solar PV inverters to provide minimum reactive power support based on the steady state operating condition. Further, solar PV inverters are required to follow specific control rule within a given capability range as described in Section II-B.

Minimum Solar PV inverter reactive power capability required in grid code regulation depends on the rating of the power plant, and point of common coupling (PCC) voltage level. Moreover, minimum reactive power requirements vary from system to system depending on the system strength and characteristics.

Fig. 1 shows mandated reactive power requirements from PVPP in four different TSO jurisdictions, where $P_{\max }$ refers to the maximum active power generation of the solar PV array/plant. It can be observed that the strictest requirement of reactive power operating range is in Ireland where solar PV inverters at transmission voltage level are required to have a mandatory reactive power capability of more than half of the installed solar PV array power [13]. California Independent System Operator (CAISO), Spanish and German grid operators have relatively less strict mandatory reactive power requirement. In this study, Germany's minimum reactive power requirement is considered to be mandatory reactive power reserve $Q_{\text {mand }}$.

\section{B. Reactive Power Control Modes of Large Scale PVPP}

Decoupled control of power inverter has enabled the inverter to operate in different reactive power control modes without compromising maximum power point tracking (MPPT) operation. Solar PV inverters are generally controlled in one of three modes, reactive power, power factor or voltage control mode. In reactive power control mode, inverter exchange reactive power with the grid based on the reference value of $\mathrm{Q}$ set by the plant operator. In power factor control, on the other hand, reactive power is exchanged by the inverter to maintain the desired power factor at the inverter terminal. Reactive power or power factor modes are primarily used in solar PV inverters connected to distribution system. However, voltage control mode, primarily based on Q-voltage (Q-V) droop, is generally adopted in inverters connected to transmission network. It is important to note that in all the three control $(\mathrm{Q}$, power factor, voltage) modes, inverter reactive power is controlled within the mandated reactive power range described in Section II-A. As large scale PVPPs are typically connected to transmission systems, voltage control mode is followed in this paper.

In voltage control mode, $\mathrm{Q}-\mathrm{V}$ droop slope is set as required by TSO to regulate the grid voltage within acceptable range, [0.9-1.1] pu. Reactive power support from PVPP beyond mandatory requirement (described in Section II-A), which might be required to bring voltage to its set point is considered as ancillary service [13], [15].

Solar PV inverters are designed based on peak power rating of solar PV arrays, however, for major portion of the day solar irradiance is less than the maximum designed irradiance $\left(1000 \mathrm{~W} / \mathrm{m}^{2}\right)$. Therefore, due to high margin for reactive power support, PVPPs have great potential to participate in voltage control ancillary service, thus potentially allowing the plant operator to earn additional revenue from $Q$ ancillary service market. On the other hand, from TSO prospective, participation of large scale PVPP would help securing the system voltage without the need of installing additional reactive power compensation devices in the grid.

\section{Proposed Method for Accurate Reactive} Power Capability of a Single Solar PV InVERTER

In order to estimate reactive power reserve from solar PV plant, reactive power capability curves of individual solar PV inverters should be known. While there has been reasonable focus on finding reactive power capability of wind power plant [16]-[18], calculation of reactive power capability of solar PV power plant has received a limited attention so far.

Typical solar PV inverter system is comprised of several solar PV modules connected in series and parallel to build desired voltage and current, which in turn is interfaced to the grid through inverter and a step-up transformer, as shown in Fig. 2. For realistic estimation of reactive power capability of solar PV plant, it is important to consider critical factors in calculation of individual solar PV inverter Q capability. Such factors that affect the reactive power capability of solar PV inverter can be classified into three categories, as described below. 


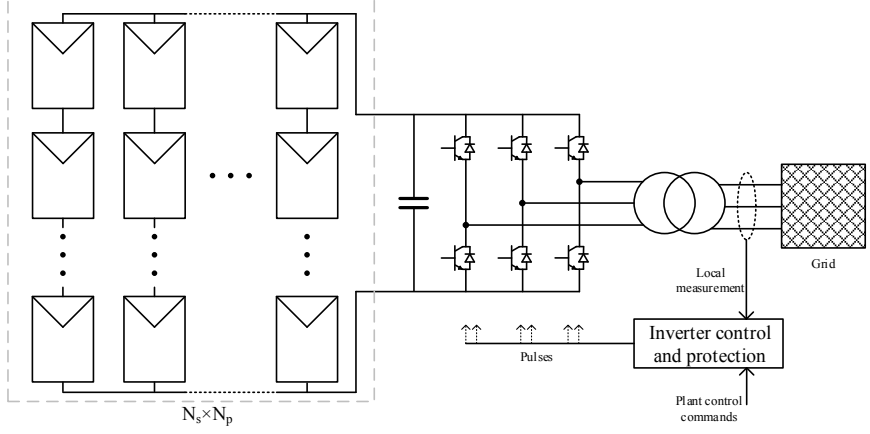

Fig. 2: Solar PV inverter system

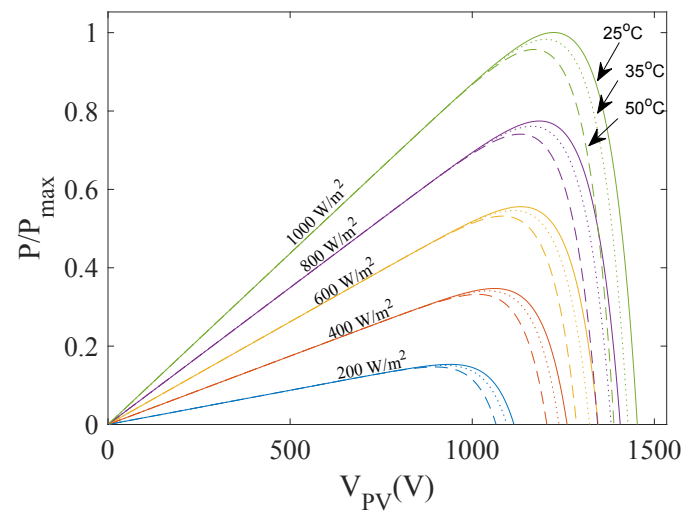

Fig. 3: Solar PV array performance under different irradiance and temperature

\section{A. Impact of solar irradiance and ambient temperature on solar PV array output}

Active power produced by solar PV arrays is highly dependent on solar irradiance and ambient temperature. Mathematical equations that govern active power produced by solar PV array are given in [19]. Fig. 3 shows performance of a solar PV array (specifications provided in the Appendix) under different solar irradiance and ambient temperature. It can be observed from Fig. 3, that active power output of solar arrays, is highly sensitive to solar irradiance and ambient temperature, with reduced capability at higher ambient temperature. Consequently, as active power delivered to grid by the inverter changes with such factors, reactive power reserve/margin of the inverter changes accordingly as given in (1).

$$
Q_{r e s}\left(G, T_{a}\right)=\sqrt{S_{r}^{2}-P^{2}\left(G, T_{a}\right)}
$$

Where $S_{r}$ is the rated apparent power of inverter, $P\left(G, T_{a}\right)$ is the active power produced by solar array connected to the inverter as a function of ambient temperature $\left(T_{a}\right)$ and irradiance $(G)$.

\section{B. Impact of ambient temperature on solar PV inverter per- formance}

Ambient temperature directly influences inverter current carrying capability, as increased ambient temperature decreases heat dissipation from power electronic switches to ambient
TABLE I: Specifications of solar PV inverters

\begin{tabular}{|c|c|c|c|c|c|c|c|c|}
\hline$\#$ & Manufacturer & $\begin{array}{c}S_{1} \\
(\mathrm{MVA})\end{array}$ & $\begin{array}{c}S_{2} \\
(\mathrm{MVA})\end{array}$ & $\begin{array}{c}S_{3} \\
(\mathrm{MVA})\end{array}$ & $\begin{array}{c}T_{0} \\
\left({ }^{\circ} \mathrm{C}\right)\end{array}$ & $\begin{array}{c}T_{1} \\
\left({ }^{\circ} \mathrm{C}\right)\end{array}$ & $\begin{array}{c}T_{2} \\
\left({ }^{\circ} \mathrm{C}\right)\end{array}$ & $\begin{array}{c}T_{3} \\
\left({ }^{\circ} \mathrm{C}\right)\end{array}$ \\
\hline 1 & SMA [23] & 4.6 & 3.91 & 0 & -25 & 25 & 50 & 60 \\
\hline 2 & ABB [24] & 4.4 & 4 & - & -20 & 35 & 50 & - \\
\hline 3 & SMA [23] & 4 & 3.4 & 0 & -25 & 25 & 50 & 60 \\
\hline 4 & SMA [25] & 3 & 2.7 & 0 & -25 & 35 & 50 & 60 \\
\hline 5 & ABB [26] & 2.4 & 2 & - & -20 & 20 & 45 & - \\
\hline 6 & SMA [25] & 2.2 & 2 & 0 & -25 & 35 & 50 & 60 \\
\hline 7 & SMA [27] & 2.2 & 2.06 & - & -25 & 40 & 50 & - \\
\hline
\end{tabular}

environment, which in turns lead to increased junction temperature of power electronic switches [20]. Therefore, for safe operation of the device/switches under high ambient temperature, additional remedial actions are required.

To avoid inverter component overheating due to increased ambient temperature, solar PV inverter manufacturers advise derated operation of the inverter, thus maximum power that can be delivered by the inverter under high ambient temperature [21], [22]. While the maximum temperature has nonlinear dependence on ambient temperature [20], solar PV inverter manufacturers tend to use a linear derating characteristic [21], [22], as given by (2).

$$
S_{r t}\left(T_{a}\right)= \begin{cases}S_{r}=S_{1}, & \text { if } T_{0} \leq T_{a} \leq T_{1} \\ S_{r} \times \frac{S_{1}-S_{2}}{T_{1}-T_{2}}, & \text { if } T_{1}<T_{a} \leq T_{2} \\ S_{r} \times \frac{S_{2}-S_{3}}{T_{2}-T_{3}}, & \text { if } T_{2}<T_{a} \leq T_{3} \\ 0, & \text { if } T_{3}<T_{a}\end{cases}
$$

Where $S_{r t}$ is the derated power of the inverter, $T_{0} \ldots T_{3}$ and $S_{1} \ldots S_{3}$ are ambient temperature in ${ }^{\circ} \mathrm{C}$ and dearted power in MVA, respectively, with their typical values given in Table I. It can be observed from Table I that inverter derating starts when ambient temperature exceeds particular threshold, mostly in the range of $\left(25-35^{\circ} \mathrm{C}\right)$. Further, beyond ambient temperature of around $50{ }^{\circ} \mathrm{C}$, sharp decrease in power carrying capacity is required, before the inverter is tripped when ambient temperature exceeds $60{ }^{\circ} \mathrm{C}$. While the inverter is disconnected when ambient temperature exceeds $60^{\circ} \mathrm{C}$.

Since maximum current carrying capacity of solar PV inverter decreases with the increase in ambient temperature, inverter reactive power capability is also significantly affected. Therefore, to calculate realistic reactive power capability of inverter, it is important to take inverter derating into consideration, hence, inverter reactive power reserve (1) can be modified by replacing $S_{r}$ with $S_{r t}\left(T_{a}\right)$ as given in (3).

$$
Q_{r e s}\left(G, T_{a}\right)=\sqrt{S_{r t}^{2}\left(T_{a}\right)-P^{2}\left(G, T_{a}\right)}
$$

Reactive power capability of the 4.6 MVA SMA inverter with its parameters provided in the Appendix, for specific solar irradiance and a varying ambient temperature is shown in Fig. 4. It can be observed from Fig. 4 that for a given active power output from solar PV inverter, reactive power capability is significantly reduced due to increased ambient temperature driven derating of the inverter. It is, however, worthy to note 


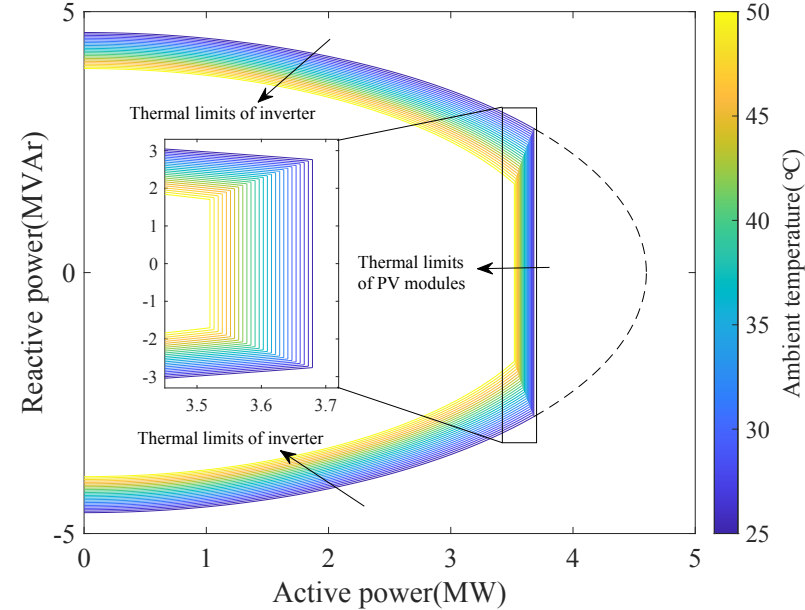

Fig. 4: Solar PV system performance under different ambient temperatures for $\mathrm{G}=1000 \mathrm{~W} / \mathrm{m}^{2}$ and $\mathrm{V}=1 \mathrm{pu}$.

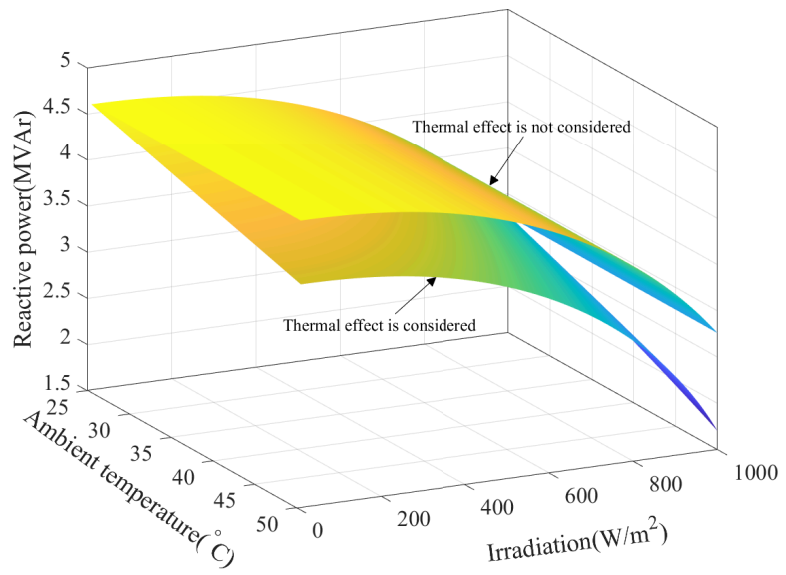

Fig. 5: Solar PV system Q capability under different ambient temperatures and irradiance, $\mathrm{V}=1 \mathrm{pu}$.

that reduction of solar PV array power generation due to the increased ambient temperature can to some extent offset decrease in inverter reactive power reserve, as can also be concluded from (3).

Impact of ambient temperature on the SMA test inverter reactive power capability under different solar irradiance is also investigated with results shown in Fig. 5 assuming solar PV inverter operates at maximum power point. It can be observed from Fig. 5 that ambient temperature has a significant impact on inverter reactive power capability, particularly, at high irradiance level.

\section{Impact of inverter terminals voltage on PV inverter reactive power capability}

Inverter terminal voltage can affect inverter reactive power capability as the terminal voltage influences current magnitude through inverter switches for a given apparent power. To incorporate inverter terminal voltage in $\mathrm{Q}$ capability equation, (3) can be modified as given in (4).

$$
Q_{r e s}\left(G, T_{a}, V\right)=\sqrt{S_{r t v}^{2}\left(T_{a}, V\right)-P^{2}\left(G, T_{a}\right)}
$$

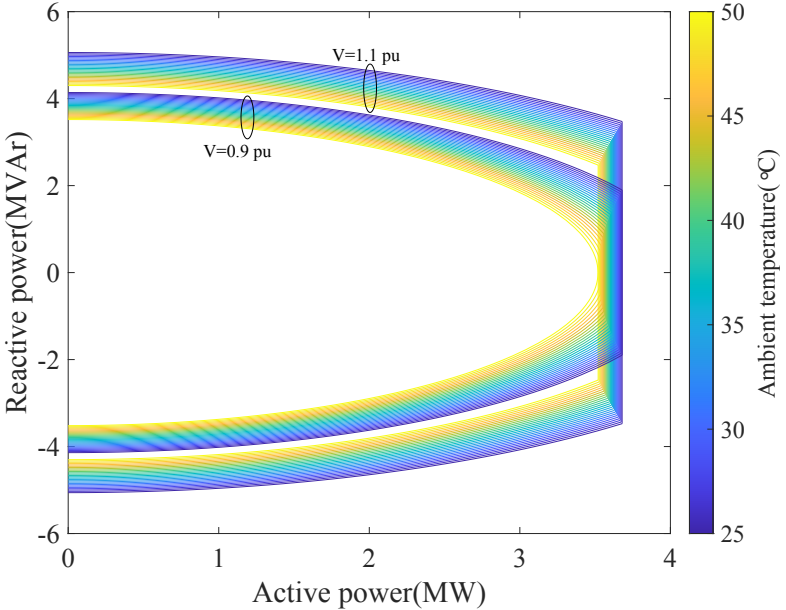

Fig. 6: Solar PV system performance under different ambient temperatures for $\mathrm{G}=1000 \mathrm{~W} / \mathrm{m}^{2}$ for $\mathrm{V}=0.9 \mathrm{pu}$ and $\mathrm{V}=1.1 \mathrm{pu}$.

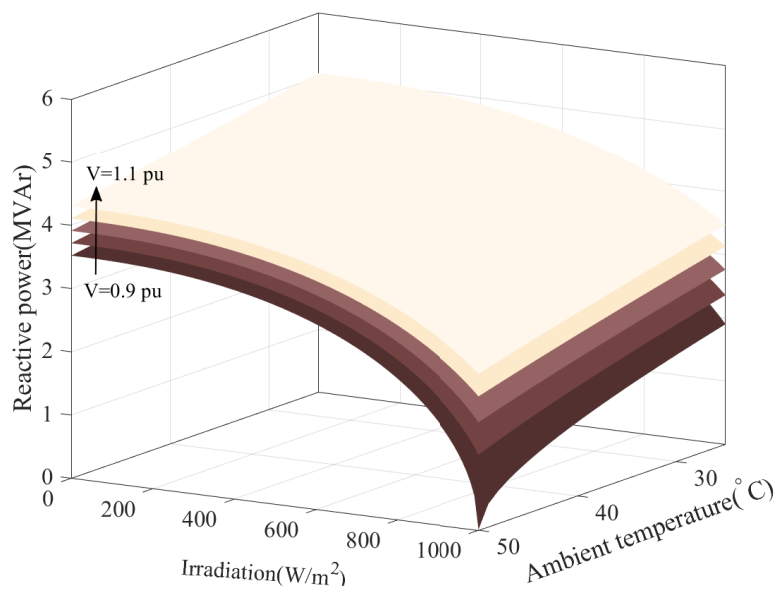

Fig. 7: Solar PV system Q capability under different ambient temperatures and irradiance and voltages

Where $S_{r t v}=V \times S_{r t}, V$ is the solar PV inverter terminals voltage in $\mathrm{pu}$, in the range of (0.9-1.1 pu).

Reactive power capability of the SMA test inverter under irradiance of $1000 \mathrm{~W} / \mathrm{m}^{2}$, varying ambient temperature, and two terminal voltages, 0.9 pu and 1.1 pu has also been studied, as shown in Fig. 6. It can be observed that decrease in terminal voltage at high ambient temperature results in decreased reactive power capability of the inverter. On the other hand, higher terminal voltage can result in higher reactive power reserve under the same conditions, which can be attributed to lower current required from the inverter for a given power. Fig. 7 shows reactive power capability curves under different irradiance, ambient temperature, and inverter terminal voltage. It can be observed from Fig. 7 that inverter reactive power capability is minimum at high ambient temperature, high solar irradiance and low terminal voltage.

\section{Proposed Adaptive Voltage Control Scheme FOR PVPP ANCILlARY SERVICE SUPPORT}

As described in Section II, large scale PVPP are connected at transmission voltage level, and can support the grid voltage 


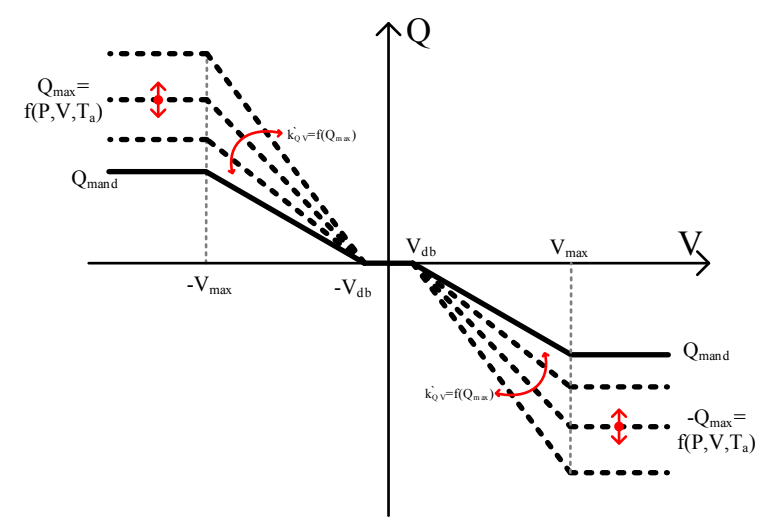

Fig. 8: Conventional fixed QV droop (bold line) and proposed adaptive QV droop (dashed lines)

by operating in voltage control mode. Fig. 8 shows conventional fixed Q-V droop characteristic (bold black line) used to comply with mandatory reactive power control requirements, where $Q_{\text {mand }}$ and $V_{\max }$ values are taken from grid code regulation, Fig. 1.

Solar PV inverter Q capability, as discussed in Section III, is significantly influenced by variation in ambient temperature, solar irradiance, and PV inverter terminal voltage. The fixed Q-V droop can be expressed as given by (5).

$$
Q=k_{Q V} * \Delta V
$$

Where $k_{Q V}$ is fixed, predefined $\mathrm{QV}$ droop and $\Delta V$ is the voltage deviation from the set point at the inverter terminal.

On the other hand, in practice, solar irradiance is not at peak for most of the day, which allows inverter to supply/consume additional reactive power beyond mandatory requirements. Therefore, to utilise this untapped reactive power reserve, and support the grid beyond mandatory requirements, self-adaptive $\mathrm{Q}-\mathrm{V}$ droop control is proposed for large scale PVPP. In the proposed control scheme, $\mathrm{QV}$ droop adapts to varying reactive power capability of the inverter as formulated in (4) as shown in Fig. 8. In other words, increase of reactive power capability result in higher QV droop, and hence larger Q contribution from the solar PV inverter towards regulating its terminals voltage. The self-adaptive $\mathrm{QV}$ droop can be formulated as given in (6).

$$
Q=k_{Q V}^{\prime} * \Delta V
$$

Where $k_{Q V}^{\prime}=-\frac{Q_{\max }\left(P, T_{a}, V\right)}{V_{\max }-V_{d b}}$ and $Q_{\max }$ is calculated as given in (4). $V_{d b}$ is the deadband voltage, which is used to avoid undesirable control triggering, as shown in Fig. 8.

To implement the proposed self-adaptive Q-V droop, the control scheme shown in Fig. 9 has been used, where maximum reactive power capability is calculated based on measured terminals voltage, active power and ambient temperature. It is worth to note that high power inverters are equipped with ambient temperature measurement provision, which is used for inverter overheating protection [22], [23]. The maximum reactive power capability of the inverter calculated for a given operating conditions (irradiance, ambient temperature, and

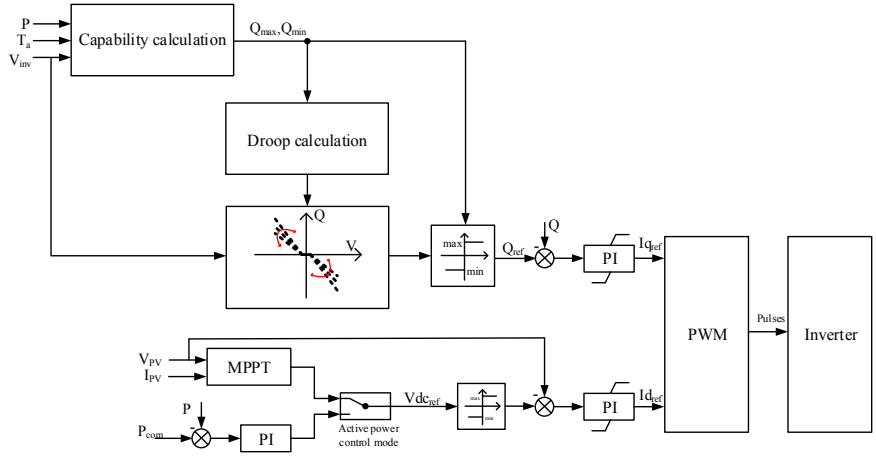

Fig. 9: Proposed adaptive QV droop control

terminal voltage) is then used for adaptive droop calculation and to limit maximum reactive power exchange of the inverter. Reactive power reference for the PV inverter is generated from the adaptive droop block based on the measured terminal voltage as given in (6).

Active power supplied by the inverter, on the other hand, is controlled based on MPPT reference, or set by the solar unit operator command $\left(P_{\text {com }}\right)$. Commanded reactive and active power from the inverter are compared with the measured values and the error is passed through proportional-integral (PI) controllers to generate current commands. The dq components of current commands are then used to generate PWM pulses to control the inverter switches.

\section{REsults}

The results, in line with the methodologies described in Section III and IV, are done in two stages. In the first stage, the methodology of calculating accurate reactive power capability of inverter is implemented, and participation of large scale PVPP in voltage control ancillary service under different ambient temperature, solar irradiance, and terminal voltage is evaluated. In the second stage, performance of the proposed self-adaptive Q-V droop control scheme for large scale PVPP under various sets of disturbances is performed in time domain simulation.

\section{A. Impact of ambient temperature on solar PV inverter reac- tive power capability}

To study the impact of high ambient temperature on solar PV inverter reactive power capability, 24 hour solar irradiance and ambient temperature data of two locations have been used in a SMA solar PV inverter with its specification provided in the Appendix.

The first location considered is in Al Qaseem, Saudi Arabia, whose solar irradiance and ambient temperature for 24 hours are shown in Fig. 10(a) [28]. It can be observed from Fig. 10 (a) that ambient temperature reaches to approximately $45^{\circ} \mathrm{C}$ in afternoon hours, while solar irradiance touches $1000 \mathrm{~W} / \mathrm{m}^{2}$ around noon time. Fig. 10 (b) shows active power generated from the studied solar PV system with and without considering ambient temperature. It is assumed that solar PV system is operating in MPPT mode during the entire day, while the solar PV inverter stays grid connected at night for voltage support, 


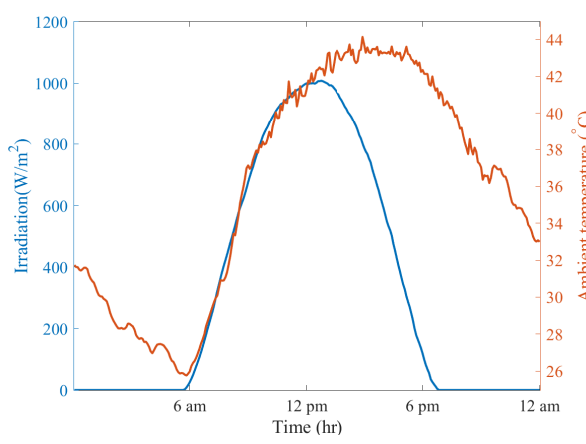

(a)

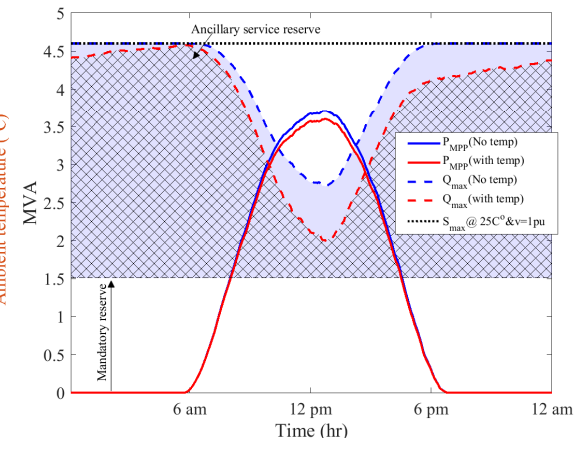

(b)

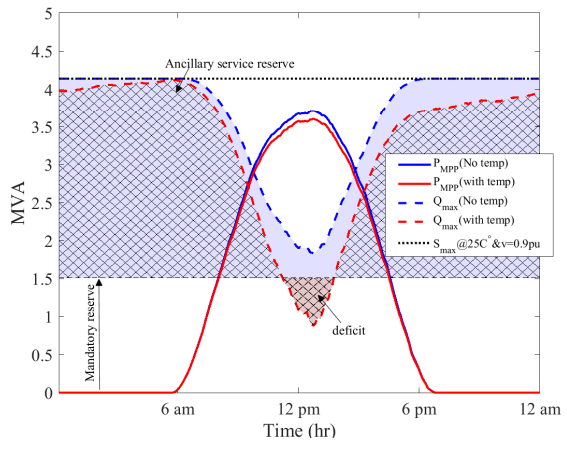

(c)

Fig. 10: PV system performance under weather conditions: Al Qaseem, Saudi Arabia, 04/08/2002 [28]. (a) Ambient temperature and solar irradiance, (b) active power and reactive power reserve for $\mathrm{v}=1 \mathrm{pu},(\mathrm{c})$ active power and reactive power reserve for $\mathrm{v}=0.9 \mathrm{pu}$

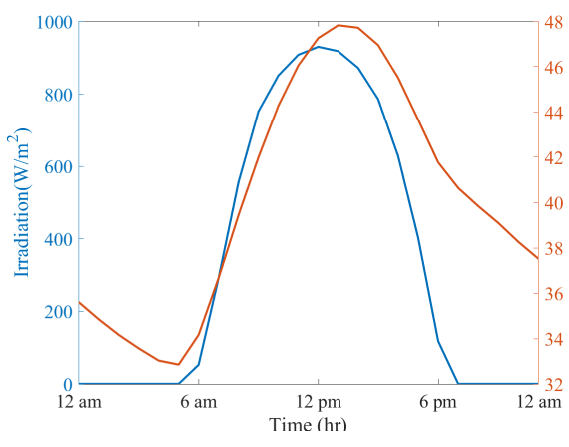

(a)

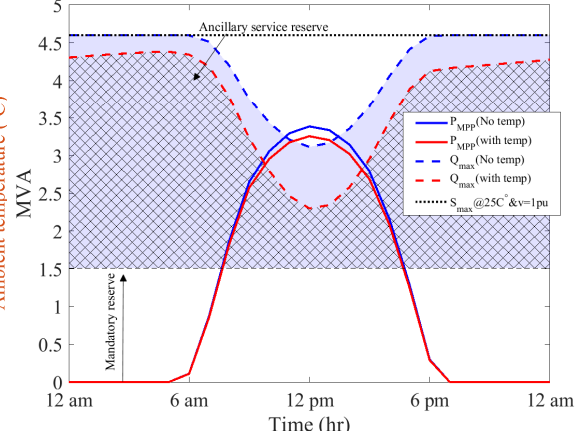

(b)

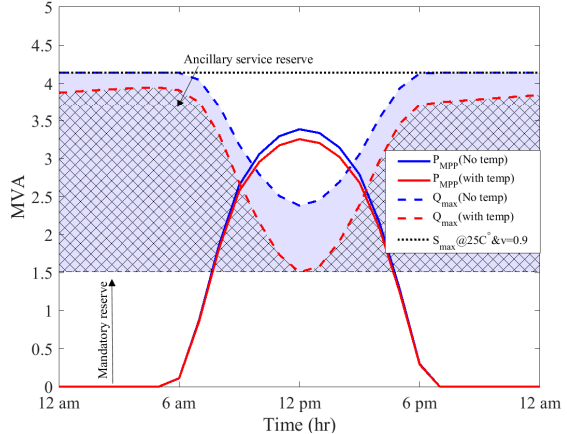

(c)

Fig. 11: PV system performance under weather conditions: Bikaner, India, 24/06/2002 [29]. (a) Ambient temperature and solar irradiance, (b) active power and reactive power reserve for $\mathrm{v}=1 \mathrm{pu}$, (c) active power and reactive power reserve for $\mathrm{v}=0.9 \mathrm{pu}$

and terminals voltage is initially assumed to be $1 \mathrm{pu}$ during the entire period. Minimum reactive power requirement, as per German grid code regulation, is represented by the bottom horizontal line, as shown in Fig. 10. The blue shaded area calculated using conventional approach represents untapped reactive power reserve that can be utilised for voltage control ancillary service beyond the grid code requirements. However, the Q reserve (shaded area) is not accurate as it is calculated without considering impact of ambient temperature on PV array and PV inverter. A significant difference in reactive power reserve can be observed between the proposed methodology (hatched area) and conventional approach of Q-reserve calculation as the ambient temperature rises over $25^{\circ} \mathrm{C}$. Therefore, it can be concluded that ignoring ambient temperature in the $\mathrm{Q}$ reserve calculation, may result in overestimation of the reserve. Fig. 10(c) presents active power and reactive power reserve of the inverter under the same conditions, however, at lower terminals voltage, $0.9 \mathrm{pu}$. An important observation under low terminal voltage condition is that by considering the realistic constraints, even mandatory reactive power requirements may not be met for short period of time during the day when ambient temperature and solar irradiance are high, as shown in Fig. 10(c). Therefore, ignoring ambient temperature in $\mathrm{Q}$ reserve calculation results in false overestimation of the inverter capability, and thus the bottleneck operating points which may even result in breaching mandatory grid code regulation cannot be observed under conventional approach of Q-reserve calculation.
Similar study has been carried out for another location, Bikaner, in Rajasthan state of India, and corresponding results are shown in Fig. 11. Solar irradiance and ambient temperature data for this location is taken from [29]. From Fig. 11(a), it can be observed that ambient temperature for Bikaner location rises to as high as $48^{\circ} \mathrm{C}$, however, with solar irradiance less than $1000 \mathrm{~W} / \mathrm{m}^{2}$. This reduction in irradiance has a mitigation effect on Q reserve, as can be observed from Fig. 11(b) compared with that in Fig. 10(b). The significant reduction of $\mathrm{Q}$ reserve during night in Fig. 11(b) compared to that in Fig. 10(b) at night is due to the high ambient temperature in the former case (Indian site) compared to the later one (Saudi site). Moreover, due to the reduced solar irradiance, mandatory reactive power requirements are almost met without deficit for low terminal voltage $(0.9 \mathrm{pu})$ as shown in Fig. 11(c).

It is uesful to note that in both the studied locations, maximum solar irradiance and ambient temperature peak do not coincide, as the ambient temperature peak occurs with some delay. This delay helps in improving minimum $\mathrm{Q}$ reserve that would otherwise be further reduced in case the two factors coincide with each other.

\section{B. Performance of the proposed self-adaptive $Q V$ droop con- trol scheme}

In order to study the performance of the proposed control scheme, a detailed large scale PVPP developed in DIgSILENT PowerFactory is connected to bus 38 in IEEE 39 bus system, as shown in Fig. 12, with PVPP layout as given in [7], [30]. The 


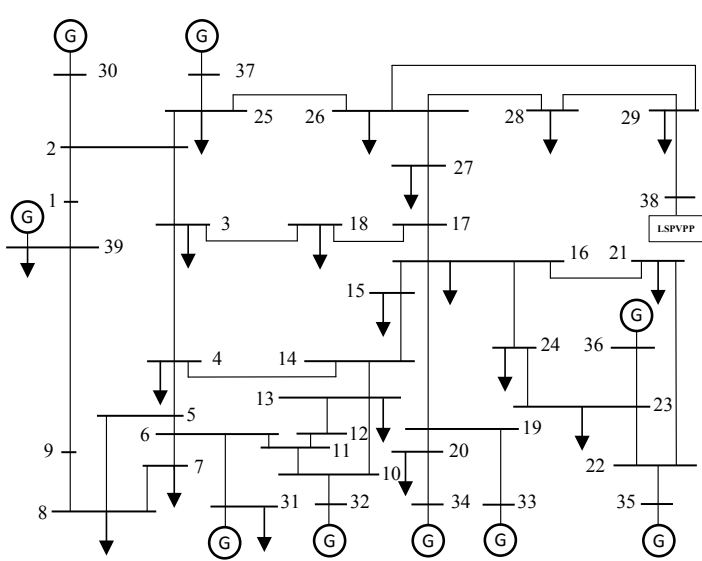

Fig. 12: IEEE 39 bus system [31].

capacity of PVPP is same as that of the displaced synchronous generator connected at bus 38. The system and the PVPP are built and simulated in DIgSILENT PowerFactory.

An additional reactive power load is connected through a circuit breaker at bus 28 to simulate a voltage dip at PVPP terminal at $\mathrm{t}=0.5 \mathrm{sec}$. Solar irradiance level and ambient temperature are assumed to be $1000 \mathrm{~W} / \mathrm{m}^{2}$ and $25^{\circ} \mathrm{C}$, respectively. Response of large scale PVPP to the voltage dip is shown in Fig. 13(a), where it can be observed that reactive power generated by the PVPP connected at bus 38 is higher in the proposed adaptive $\mathrm{QV}$ droop compared to the fixed droop, which can be attributed to utilisation of untapped reactive power reserve of the solar PV inverters by the proposed adaptive control scheme, described in Section IV. This additional reactive power supply has resulted in an improvement in the terminals voltage as can be observed from PCC voltage shown in Fig. 13(a). Response of a single inverter to the voltage event at the PVPP terminal is shown in Fig. 13(b), where higher QV droop gain can be observed when adaptive control scheme is used compared to fixed droop scheme. The adaptive droop is reduced after the disturbance due to the reduced inverter voltage terminals, which in turn reduces $Q_{\max }$.

For a comprehensive analysis of the proposed control scheme, a time series load variation is introduced in IEEE 39 bus system to apply voltage variations at PVPP terminals. Further, to incorporate seasonal variation, three different weather conditions are considered, viz., high solar irradiance with low and high ambient temperature, and low solar irradiance and ambient temperature as shown in Fig. 14. It can be observed from Fig. 14 that large scale PVPP reduces terminal voltage variations in case of adaptive QV droop compared to fixed QV droop, which can be attributed to higher dynamic reactive power compensation under the adaptive QV droop. Moreover, PVPP under adaptive QV control in the first case, Fig. 14(a), outperforms the PVPP dynamic behaviour compared to case 2, Fig. 14(b). This is due to the higher reactive power reserve of the PVPP under lower ambient temperature, which is reflected in higher QV droop in the first case compared to the second case. In the third case, Fig. 14(c), PVPP shows a better performance than the first two cases due to lower

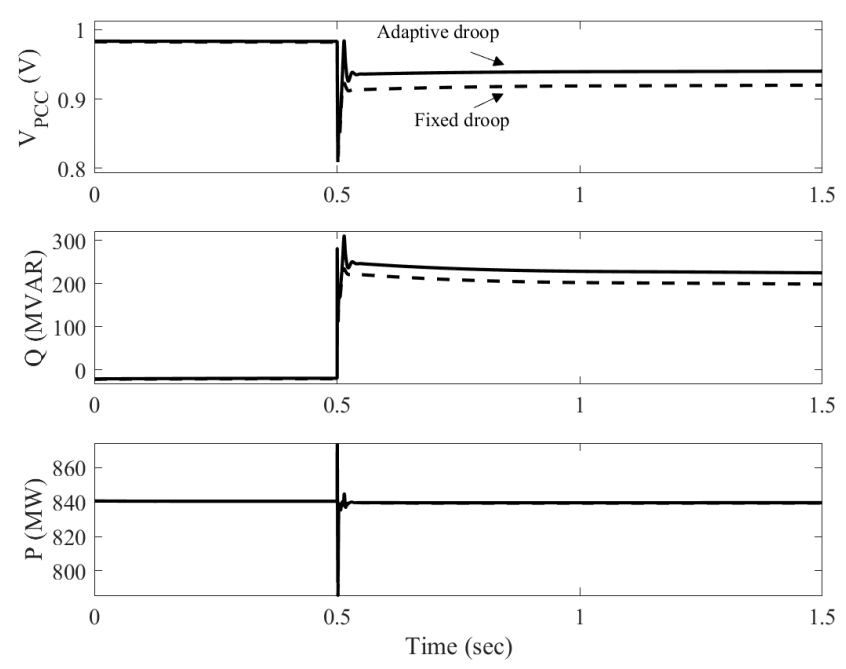

(a)
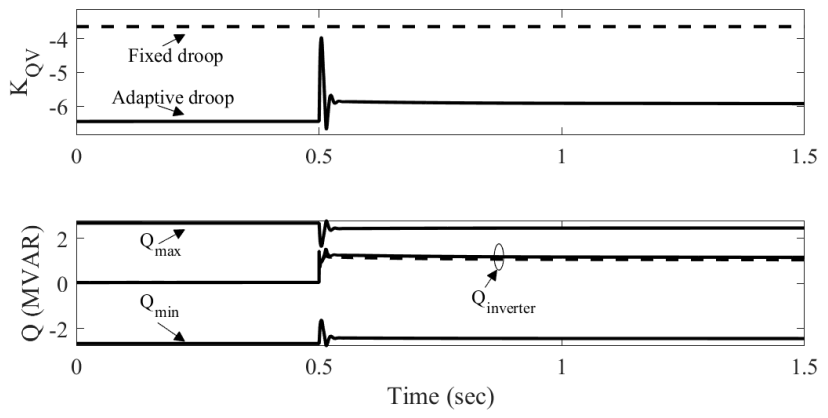

(b)

Fig. 13: (a) PVPP response to voltage dip. (b) A single solar PV inverter response to voltage dip.

solar irradiance level, and hence having higher reactive power reserve and better QV droop.

\section{Discussions AND CONCLUSIONS}

In this paper, reactive power capability of solar PV inverters is studied considering variation in solar irradiance, ambient temperature and terminal voltage. Based on the proposed accurate and realistic reactive power capability calculation, a self-adaptive QV droop control is proposed to utilise reactive power reserve of large scale PVPP for voltage control ancillary service. The following concluding points are drawn from this paper.

- Considering ambient temperature impact on solar PV arrays only to estimate reactive power capability of solar PV inverter may lead to over estimation of reactive power capability of the system. Incorporation of the impact of ambient temperature on solar PV inverter gives more accurate and realistic estimation of reactive power capability of solar PV conversion system.

- The geographical location of PVPP plays a significant role in determining its reactive power capability. Locations with a very high temperature may require oversizing solar PV inverter or installing additional reactive power sources, such as capacitors, to comply with the grid code mandatory requirements or to increase PVPP participation in voltage control ancillary service. In cold countries, 


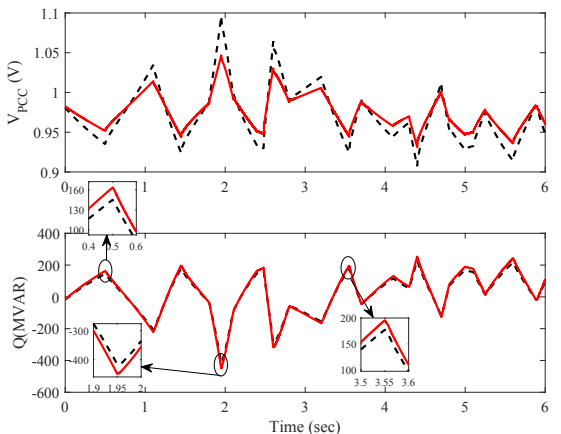

(a) $\mathrm{G}=1000 \mathrm{~W} / \mathrm{m}^{2}, \mathrm{~T}=25^{\circ} \mathrm{C}$

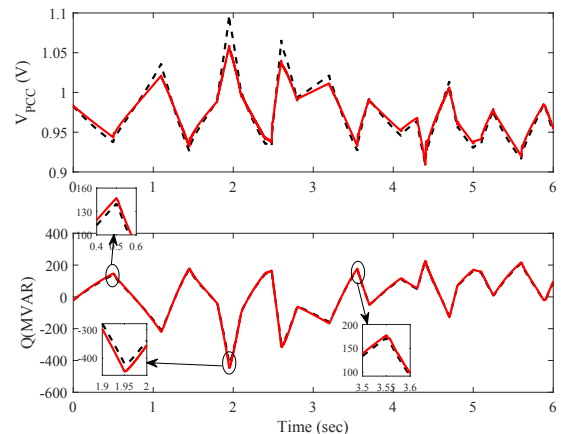

(b) $\mathrm{G}=1000 \mathrm{~W} / \mathrm{m}^{2}, \mathrm{~T}=40^{\circ} \mathrm{C}$
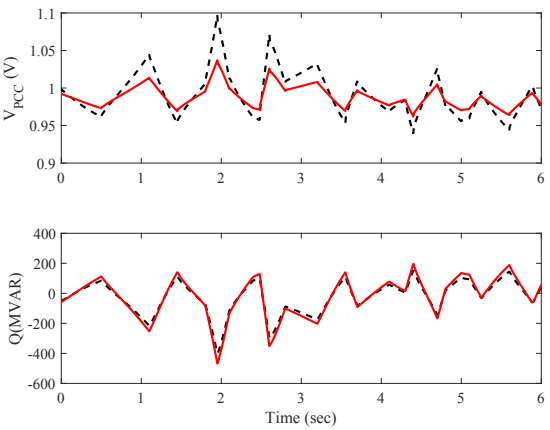

(c) $\mathrm{G}=700 \mathrm{~W} / \mathrm{m}^{2}, \mathrm{~T}=25^{\circ} \mathrm{C}$

Fig. 14: PVPP voltage control response to voltage disturbances under various irradiance and ambient temperature conditions.

TABLE II: Specifications of Solar PV module and inverter

\begin{tabular}{|c|c|c|c|}
\hline \multicolumn{2}{|c|}{ Inverter [23] } & \multicolumn{2}{|c|}{ Solar PV module @ STC [32] } \\
\hline Nominal AC voltage & $690 \mathrm{~V}$ & Nominal Power & $355 \mathrm{~W}$ \\
\hline Frequency & $50 \mathrm{~Hz}$ & $V_{M P P}$ & $43.4 \mathrm{~V}$ \\
\hline Rated AC current at $25^{\circ} \mathrm{C}$ & $3850 \mathrm{~A}$ & $I_{M P P}$ & $8.18 \mathrm{~A}$ \\
\hline Rated AC current at $50{ }^{\circ} \mathrm{C}$ & $3273 \mathrm{~A}$ & $V_{O C}$ & $51.9 \mathrm{~V}$ \\
\hline Rated AC power at $25^{\circ} \mathrm{C}$ & $4.6 \mathrm{MVA}$ & $I_{S C}$ & $8.68 \mathrm{~A}$ \\
\hline Rated AC power at $50{ }^{\circ} \mathrm{C}$ & $3.91 \mathrm{MVA}$ & Power temp. coef. & $-0.37 \% /{ }^{\circ} \mathrm{C}$ \\
\hline Max. DC voltage & $1500 \mathrm{~V}$ & Voltage temp. coef. & $-176.5 \mathrm{mV} /{ }^{\circ} \mathrm{C}$ \\
\hline Max. efficiency & $98.7 \%$ & Current temp. coef. & $3.6 \mathrm{~mA} /{ }^{\circ} \mathrm{C}$ \\
\hline
\end{tabular}

on the other hand, the change in reactive power capability of solar PV inverters is trivial.

- Large scale PVPP reactive power capability in practice differs significantly from solar PV inverter capability under standard test conditions. Incorporating practical aspects such as, weather conditions provides an accurate estimation of PVPP, which is critical for PVPP operator as well as transmission system operator.

\section{APPENDIX}

Table II shows solar PV system parameters. The number of parallel and series PV modules are $N_{p}=370$ and $N_{s}=28$.

\section{REFERENCES}

[1] P. Fairley, "The pros and cons of the world's biggest solar park," IEEE Spectrum, 2020

[2] Z. H. Rather, Z. Chen, P. Thøgersen, and P. Lund, "Dynamic reactive power compensation of large-scale wind integrated power system," IEEE Trans. Power Sys., vol. 30, no. 5, pp. 2516-2526, 2015.

[3] EirGrid and SONI, "DS3 System Services: Portfolio Capability Analysis," 2014, online: www.eirgrid.com.

[4] H. Yu, J. Pan, and A. Xiang, "A multi-function grid-connected pv system with reactive power compensation for the grid," Solar energy, vol. 79, no. 1, pp. 101-106, 2005.

[5] F. L. Albuquerque et al., "Photovoltaic solar system connected to the electric power grid operating as active power generator and reactive power compensator," Solar Energy, vol. 84, no. 7, pp. 1310-1317, 2010.

[6] A. Ellis et al., "Reactive power interconnection requirements for pv and wind plants-recommendations to NERC," Sandia National Laboratories, NM, USA, Tech. Rep., 2012.

[7] C. Loutan et al., "Demonstration of essential reliability services by a 300-MW solar photovoltaic power plant," NREL, Tech. Rep., 2017.

[8] R. K. Varma et al., "Nighttime application of pv solar farm as statcom to regulate grid voltage," IEEE Trans. Energy Conv., vol. 24, no. 4, pp. 983-985, 2009.

[9] R. K. Varma et al., "New control of PV solar farm as STATCOM (PVSTATCOM) for increasing grid power transmission limits during night and day," IEEE Trans. Power Del., vol. 30, no. 2, pp. 755-763, 2014.
[10] L. F. N. Lourenco, de Camargo Salles et al., "Technical Cost of Operating a Photovoltaic Installation as a STATCOM at Nighttime," IEEE Trans. Sustain. Energy, vol. 10, no. 1, pp. 75-81, 2018.

[11] L. Lourenço, R. Monaro, M. Salles et al., "Evaluation of the reactive power support capability and associated technical costs of photovoltaic farms operation," Energies, vol. 11, no. 6, p. 1567, 2018.

[12] K. Loudiyi et al., "Grid code status for wind farms interconnection in northern Africa and Spain: Descriptions and recommendations for northern Africa," Renew. Sustain. Energy Rev., vol. 81, 2018.

[13] EirGrid, "Grid code, version 8," Online: http://www.eirgrid.com, 2019.

[14] Tennet TSO GmbH, "Grid code, high and extra high voltage," Germany, November, 2015.

[15] "Enhanced Reactive Power: A guide to the services procured by National Grid to manage voltages on the transmission system," National Grid, available at http://www2.nationalgrid.com.

[16] N. R. Ullah, K. Bhattacharya, and T. Thiringer, "Wind farms as reactive power ancillary service providerstechnical and economic issues," IEEE Trans. Energy Conv., vol. 24, no. 3, pp. 661-672, 2009.

[17] H. Karbouj and Z. H. Rather, "Voltage control ancillary service from wind power plant," IEEE Trans. Sustain. Energy, vol. 10, no. 2, pp. 759-767, 2018

[18] M. Sarkar, M. Altin, P. E. Sørensen, and A. D. Hansen, "Reactive power capability model of wind power plant using aggregated wind power collection system," Energies, vol. 12, no. 9, p. 1607, 2019.

[19] D. Sera, R. Teodorescu, and P. Rodriguez, "PV panel model based on datasheet values," in IEEE Int. Symp. Indust. Electron., 2007.

[20] H. Zhang and L. M. Tolbert, "Efficiency impact of silicon carbide power electronics for modern wind turbine full scale frequency converter," IEEE Trans. Indust. Electron., vol. 58, no. 1, pp. 21-28, 2010.

[21] R. G. Wagoner and D. Smith, "Power system junction temperature control," Mar. 15 2016, US Patent 9,287,766.

[22] "Technical Information: Temperature derating," SMA Solar Technology AG, Tech. Rep., available at https://files.sma.de/d1/7418/ Temp-Derating-TI-en-15.pdf.

[23] "Sunny Central UP datasheet," SMA Solar Technology AG, available at https://www.sma.de/.

[24] "Solar Inverters: ABB Compact Skid for US market — PVS980-CS-US 2 to $4.4 \mathrm{MVA}, \mathrm{ABB}$, available at https://www.abb.com/.

[25] "Sunny Central 2200/2475/2500-EV/2750-EV/3000-EV datasheet," SMA Solar Technology AG, available at https://www.sma.de/.

[26] "Solar Inverters: ABB inverter station - PVS800-IS 1.75 to 2 MW," ABB, available at https://www.abb.com/.

[27] "Product specifications Conext SmartGen ${ }^{\mathrm{TM}}$ CS2200 Model," Schneider Electric, available at https://solar.schneider-electric.com/.

[28] National Renewable Energy Laboratory (NREL). NASA remote sensing validation data: Saudi Arabia. [Online]. Available: https: //www.nrel.gov/grid/solar-resource/saudi-arabia.html

[29] NREL. National Solar Radiation Database (NSRDB). [Online]. Available: https://maps.nrel.gov/nsrdb-viewer

[30] Cabrera-Tobar et al., "Review of advanced grid requirements for the integration of large scale photovoltaic power plants in the transmission system," Renew. and Sustain. Energy Rev., vol. 62, pp. 971-987, 2016.

[31] P. Demetriou et al., "Dynamic IEEE test systems for transient analysis," IEEE Syst. J., vol. 11, no. 4, pp. 2108-2117, 2017.

[32] "SunPower ${ }^{\circledR}$ Performance Series 1500 Volt p17," SunPower, available at https://us.sunpower.com/. 